\title{
FLORÍSTICA E DIVERSIDADE EM UM FRAGMENTO DE FLORESTA ESTACIONAL SEMIDECIDUAL ALUVIAL EM DOURADOS, MS
}

\author{
Laércio Arruda*, Omar Daniel** \\ *Eng. Agrônomo, M.Sc., Prefeitura Municipal de Dourados/SENSUR, Dourados, MS \\ **Eng. Florestal, Dr., Faculdade de Ciências Agrárias, UFGD - omard@ufgd.edu.br \\ Recebido para publicação: 08/05/2006 - Aceito para publicação: 28/11/2006
}

\begin{abstract}
Resumo
Foi realizada a caracterização florística de um fragmento de floresta às margens do rio Dourados (MS), em uma área com aproximadamente 100 ha. Foram traçados nove transectos utilizando o método dos quadrantes móveis, registradas as distâncias entre árvores e ângulos e coletado material botânico das plantas com circunferência à altura do peito $\geq 15 \mathrm{~cm}$. Foram analisados os seguintes índices de diversidade e de dispersão: Quociente de Mistura de Jentsch, Shannon, Simpson, Pielou e Morisita. Os valores para os quatro primeiros índices foram 1/7, 0,95, 3,48 e 0,80, respectivamente. O índice de Morisita foi calculado por espécie, obtendo-se que $64 \%$ das espécies apresentaram padrão de dispersão uniforme, $6,5 \%$ aleatório, $5 \%$ agregado e $24,5 \%$ com tendência ao agregamento, concluindo-se que a vegetação estudada encontra-se madura. A vegetação analisada apresenta alta diversidade, a mistura de espécies foi considerada intensa e encontra-se em bom estado de conservação.

Palavras-chave: Diversidade de espécies; floresta de galeria; florística; Floresta Estacional Semidecidual.
\end{abstract}

\begin{abstract}
Floristic and diversity in a riparian forest fragment in Dourados, Mato Grosso do Sul, Brazil. Floristic analysis of the riparian forest fragment located alongside the Dourados river, Mato Grosso do Sul state was described. The survey was carried out in nine transects distributing in $100 \mathrm{ha}$, using a wandering quarter method, collecting botanical parts and distances between plants with circunference at breast hight $\geq 15 \mathrm{~cm}$. Jentsch Quocient, Shannon, Simpson, Pielou and Morisita index were calculated and the values were, in order, 1/7, 0,95, 3,48 e 0,80. By Morisita index the result were: 64 $\%$ with uniform patern, $6,5 \%$ aleatory, $5 \%$ agregated and $24,5 \%$ tending to agragation, concluding that the vegetation was in close to the climax. The vegetation showed high diversity, the mixture of species was considered intense and in agreement with the obtained indexes the community is in good state of conservation.

Keywords: Diversity of species; riparian forest; floristic; Semi-deciduous Seasonal Forest.
\end{abstract}

\section{INTRODUÇÃO}

Dentre as áreas com florestas tropicais, situadas entre as coordenadas de $23^{\circ} 27^{\prime} \mathrm{N}$ e $23^{\circ} 27^{\prime} \mathrm{S}$ (LONGMAN; JENÍK, 1987), está inserido o estado de Mato Grosso do Sul, com $358.158,7 \mathrm{~km}^{2}$ de área territorial. Nesse estado observa-se o contato e a interpenetração das províncias florísticas Amazônica (Norte), Chaquenha (Oeste) e da bacia do rio Paraná (Leste/Sul). Por conseqüência, ocorrem paisagens fitogeográficas diversificadas, como estepes (campos limpos), savanas (cerrados) e formações florestais como a Floresta Estacional Semidecidual (SEPLAN, 1990).

A bacia hidrográfica do rio Paraná é uma das principais no estado de Mato Grosso do Sul e recebe a contribuição de nove sub-bacias, dentre as quais a do rio Ivinhema e de seus tributários, os rios Brilhante e Dourados. Apresenta formação vegetal característica, classificada como Floresta Estacional Semidecidual (SEPLAN, 1990), com 20 a $50 \%$ de árvores caducifólias compondo o dossel, dividindo-se em subformação das Terras Baixas, Aluvial, Submontana e Montana (IBGE, 1992). 
A Floresta Estacional Semidecidual está severamente degradada em toda a área de ocorrência natural, principalmente em função de práticas agropecuárias (DURIGAN et al., 2000). Em Mato Grosso do Sul, essa tipologia foi pouco estudada, tanto florística como fitossociologicamente, sendo poucas as referências encontradas a seu respeito (ASSIS, 1991; DAMASCENO JÚNIOR, 1997).

Por meio do estudo da composição florística e da estrutura fitossociológica de uma floresta, pode-se construir uma base teórica para subsidiar projetos de conservação de recursos genéticos, conservação de áreas similares e a recuperação de áreas ou fragmentos florestais degradados, contribuindo para seu manejo (VILELA et al., 1993; CUSTÓDIO FILHO et al., 1994a; GILHUIS, 1986, citado por DRUMOND et al., 1996). Além disso, esses estudos são importantes no estabelecimento de divisões fitogeográficas (SILVA; LEITÃO FILHO, 1982; OLIVEIRA; ROTTA, 1982; NEGRELLE; SILVA, 1992; CUSTÓDIO FILHO et al., 1994b; SOARES et al., 1994; NEGREIROS et al., 1995; CARVALHO et al., 1996; VILELA et al., 1999; WERNECK et al., 2000).

$\mathrm{O}$ sucesso de qualquer iniciativa relacionada à produção econômica de uma floresta passa pelo levantamento florístico e estudos fitossociológicos. São etapas essenciais a serem vencidas na formação de maciços florestais heterogêneos, com espécies nativas arbóreas suscetíveis a planos de manejo ecológica e economicamente rentáveis (DE PAULA et al., 1993). A complementaridade entre esses dois ramos da biologia dá suporte às interferências, subsidiando a conservação e a recuperação (VILELA et al., 1993).

As análises florísticas informam ainda sobre a composição de espécies de uma determinada comunidade vegetal, o quanto cada espécie se acha presente e como ela se distribui no ambiente (OLIVEIRA; ROTTA, 1982).

Nesse contexto, o principal objetivo deste trabalho foi a avaliação da composição florística em uma área com Floresta Estacional Semidecidual em Dourados (MS), utilizando-se o Quociente de Mistura de Jentsch, os índices de diversidade de Shannon e de Simpson, a riqueza florística através do índice de Pielou e o padrão de distribuição espacial das espécies pelo índice de Morisita.

\section{MATERIAL E MÉTODOS}

\section{Caracterização da área}

A área de estudo está localizada no município de Dourados, estado de Mato Grosso do Sul. É marginal ao rio Dourados e à rodovia MS-379 (Dourados-Laguna Carapã), km 08, medindo aproximadamente 100 ha.

A formação florestal presente na área é classificada como Floresta Estacional Semidecidual (SEPLAN, 1990). A ação antrópica é evidente, detectada por meio da retirada de espécies comerciais, efeito de borda e invasão de pastagens em pontos isolados.

A área pertence à unidade geomorfológica Planalto de Maracajú-Campo Grande, apresentando formas de dissecação tabulares e de topo aplanado, geologicamente inserida no Grupo São Bento, Formação Serra Geral. O solo predominante é o Latossolo Vermelho distroférrico, em relevo plano (BRASIL, 1982; EMBRAPA, 1999; OLIVEIRA et al., 2000).

O clima da região é definido como úmido a sub-úmido, com precipitação pluviométrica anual entre 1500 a 1750 mm (SEPLAN, 1990), classificado segundo o sistema internacional de Köppen como Cwa. A altitude local é de $452 \mathrm{~m}$.

\section{Amostragem}

O método de amostragem utilizado foi o quadrante móvel, também conhecido como wandering quarter (BROWER; ZAR, 1977), que é uma variação do método de ponto quadrante, tendo como orientação transectos paralelos. Estes foram delineados no sentido leste-oeste (Figura 1), a princípio com o objetivo de realizar estudos de gradiente, se houvesse, o que não foi detectado, provavelmente em função da pequena largura da área, da homogeneidade dos solos onde estes não eram hidromórficos e do declive (abaixo de 4 \%). Foram utilizados 9 transectos e 1680 metros lineares de caminhamento (Figura 2), distanciados de 150 a $300 \mathrm{~m}$, evitando-se na medida do possível os obstáculos naturais e procurandose recobrir possíveis variações norte-sul. As manchas de solos hidromórficos foram excluídas do levantamento. 


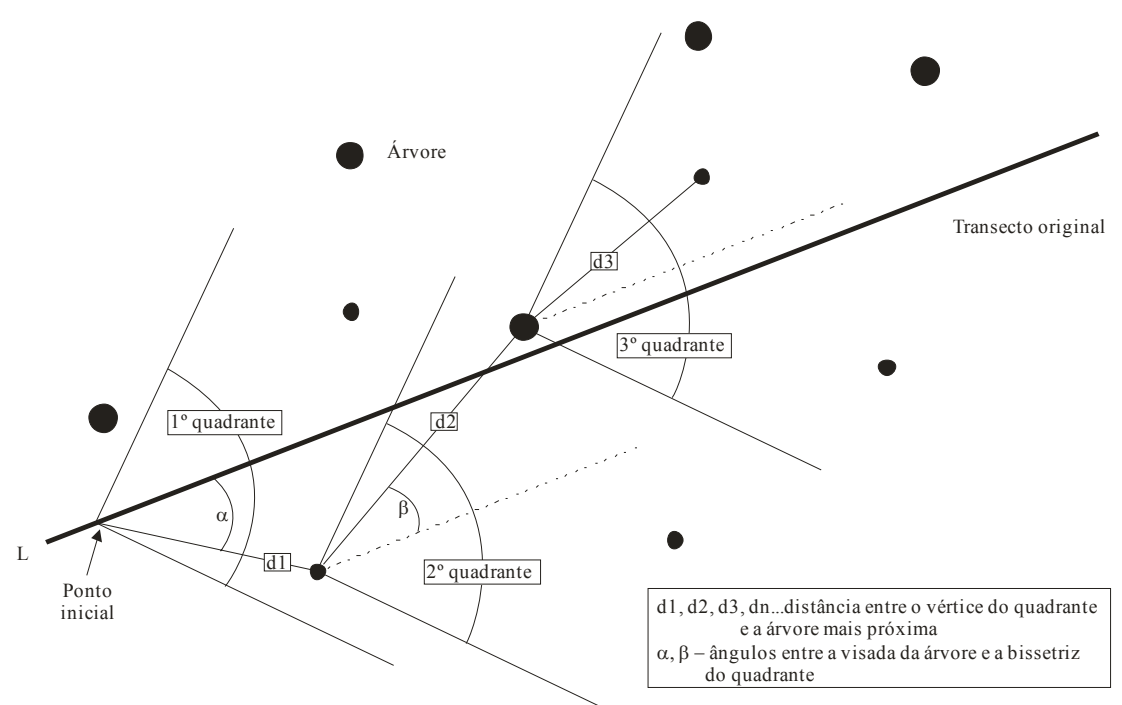

Figura 1. Representação do quadrante móvel (wandering quarter) (BROWER; ZAR, 1977). Figure 1. Image of the wandering quarter (BROWER; ZAR, 1977).

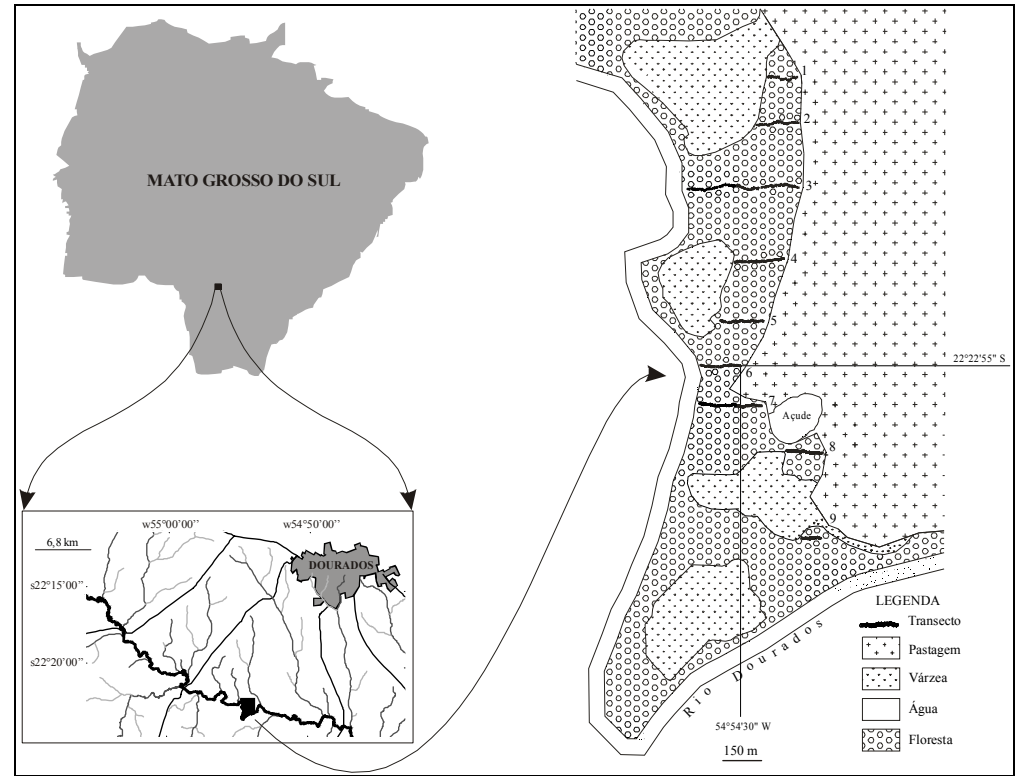

Figura 2. Representação da área com os transectos utilizados.

Figure 2. Map of the area enclosing transects.

Com o auxílio de uma bússola, fixou-se o início do transecto como vértice e bissetriz do quadrante. $\mathrm{O}$ indivíduo mais próximo do vértice, dentro do quadrante, foi amostrado e serviu de vértice para o próximo ponto, criando-se um novo transecto paralelo ao anterior. Repetiu-se o procedimento sucessivamente, causando a movimentação do quadrante. Em cada quadrante foram registradas a distância do vértice à planta e o nome comum das espécies cujo CAP fosse $\geq 15,0 \mathrm{~cm}$. Ramos com folhas, inflorescências e frutos também foram coletados, visando a confecção de exsicatas e identificação botânica. As medidas de distância entre as plantas foram aferidas com trena.

Para a identificação botânica, além da utilização de bibliografia específica para famílias, gêneros e espécies, foi necessário encaminhar parte do material para o Herbário da Universidade Federal de Mato Grosso do Sul, em Campo Grande (MS). Foram feitas exsicatas e o material está depositado no herbário local, que se encontra em construção, sem registro oficial no momento. 


\section{Análises florísticas}

Para a caracterização florística da área, visando possíveis comparações com outras formações florestais, mesmo de outros estados, foram utilizados:

a) Quociente de Mistura (QM): é usado para medir a intensidade de mistura, demonstrando a relação entre o número de espécies e o número de indivíduos amostrados. Quanto menor o denominador maior será a mistura (FINOL, 1971).

$$
\mathrm{QM}=\frac{\text { número de espécies amostradas }}{\text { número de indivíduos amostrados }}
$$

b) Índice de diversidade de Shannon (H'), com logaritmo na base neperiana (LUDWIG; REYNOLDS, 1988): é um índice relativo, portanto necessita ser comparado ao de outras áreas e tipos de florestas (SILVA; LEITÃO FILHO, 1982). A sua interpretação depende do conhecimento do nível de exclusão de DAP (diâmetro à altura do peito), do rigor utilizado para a identificação das espécies e da intensidade amostral utilizada, como demonstram Rolim e Nascimento (1997).

$$
\mathrm{H}^{\prime}=\frac{\mathrm{N} \times \ln (\mathrm{N})-\sum_{\mathrm{i}=1}^{\mathrm{n}}\left[\mathrm{n}_{\mathrm{i}} \times \ln \left(\mathrm{n}_{\mathrm{i}}\right)\right]}{\mathrm{N}} \mid \begin{aligned}
& \text { Sendo: } \mathrm{N}=\text { Número total de indivíduos } \\
& \text { amostrados. } \\
& \mathrm{n}=\text { número de espécies amostradas. } \\
& \mathrm{n}_{\mathrm{i}}=\text { número de indivíduos da espécie } \mathrm{i} . \\
& \ln =\text { logaritmo neperiano. }
\end{aligned}
$$

c) Índice de diversidade de Simpson (Ds): varia de zero a um, e quanto mais próximo de um, maior a diversidade florística da comunidade (BROWER; ZAR, 1977).

$$
\text { Ds =1-L; L = } \frac{\sum_{\mathrm{i}=1}^{\mathrm{n}} \mathrm{n}_{\mathrm{i}}\left(\mathrm{n}_{\mathrm{i}}-1\right)}{\mathrm{N}(\mathrm{N}-1)} \quad \begin{aligned}
& \begin{array}{l}
\text { Sendo: } \mathrm{N}=\text { Número total de indivíduos } \\
\text { amostrados. } \\
\mathrm{n}=\text { número de espécies amostradas. } \\
\mathrm{n}_{\mathrm{i}}=\text { número de indivíduos da espécie } \mathrm{i} .
\end{array}
\end{aligned}
$$

d) Índice de Pielou (J): representa a proporção da diversidade de espécies encontradas na amostragem atual em relação à diversidade máxima que a comunidade poderá atingir (BROWER; ZAR, 1984), e também a uniformidade da repartição dos indivíduos entre as espécies (ODUM, 1986).

$$
\begin{array}{l|l}
\mathrm{J}^{\prime}=\frac{\mathrm{H}^{\prime}}{\mathrm{H}^{\prime}{ }_{\max }} & \begin{array}{l}
\text { Sendo: } \mathrm{H}_{\text {max }}^{\prime}=\ln (\mathrm{n}) . \\
\mathrm{n}=\text { número de espécies amostradas. } \\
\mathrm{H}^{\prime}=\text { índice de Shannon-Weaver. }
\end{array}
\end{array}
$$

$\mathrm{Na}$ interpretação desse índice, o valor mínimo é zero e o máximo um, representando eqüitabilidade baixa e alta, respectivamente. Quando multiplicado por 100, apresenta em porcentagem a diversidade atual em relação à máxima possível.

e) Índice de agregação de espécies de Morisita (Id): é pouco influenciado pelo tamanho das parcelas e excelente indicador do grau de dispersão (BARROS; MACHADO, 1984).

$$
\mathrm{Id}_{\mathrm{i}}=\frac{\sum_{\mathrm{j}=1}^{\mathrm{p}} \mathrm{n}_{\mathrm{ij}}\left(\mathrm{n}_{\mathrm{ij}}-1\right)}{\mathrm{N}(\mathrm{N}-1)} \quad \begin{aligned}
& \begin{array}{l}
\text { Sendo: } \mathrm{n}_{\mathrm{ij}}=\mathrm{n}^{\mathrm{o}} \text { de indivíduos da espécie } \mathrm{i} \text { na unidade } \\
\text { amostral } \mathrm{j} . \\
\mathrm{n} \mathrm{e} \mathrm{p}=\mathrm{n}^{\mathrm{o}} \text { de espécies e de parcelas, respectivamente. }
\end{array} \\
& \mathrm{N}=\text { número total de indivíduos da espécie } \mathrm{i} .
\end{aligned}
$$

Os padrões para a interpretação desse índice são os seguintes:

\begin{tabular}{lc}
\hline Índice de Morisita & Padrão \\
\hline 0 & uniforme \\
1 & aleatório \\
igual a $\mathrm{p}$ & agregado \\
$1<\mathrm{Id}<10$ e $\chi^{2}$ calculado $>\chi^{2}$ tabelado & tendência ao agregamento
\end{tabular}

O teste $\chi^{2}$ é usado para examinar estatisticamente os padrões em relação à aleatoriedade, a p-1 graus de liberdade. Se a diferença for significativa, o padrão não é aleatório, tendo, portanto, tendência ao agregamento (BROWER; ZAR, 1977). A fórmula para o cálculo do $\chi^{2}$ é: 


$$
\chi_{\text {calculado }}^{2}=\frac{\mathrm{n} \sum \mathrm{X}^{2}}{\mathrm{~N}}-\mathrm{N} \quad \begin{aligned}
& \begin{array}{l}
\text { Sendo: } \mathrm{X}=\text { número de indivíduos da espécie por parcela. } \\
\mathrm{n}=\text { número de parcelas. } \\
\mathrm{N}=\text { número total de indivíduos da espécie. }
\end{array}
\end{aligned}
$$

\section{RESULTADOS E DISCUSSÃO}

Foram amostrados 572 indivíduos pertencentes a 76 espécies, 54 gêneros e 29 famílias (Tabela 1), com densidade de 1024 indivíduos por hectare. Do total de espécies, 18 foram identificadas apenas em nível de gênero e cinco não foram identificadas. Valores semelhantes em Florestas Estacionais Semideciduais foram encontrados por Durigan et al. (2000) em Gália (SP), com 76 espécies e 32 famílias, e por Fonseca e Rodrigues (2000) em Botucatu (SP), com 61 espécies, 50 gêneros e 31 famílias, totalizando 1104 árvores por hectare.

Alguns gêneros típicos de Floresta Estacional Semidecidual Submontana apareceram (Aspidosperma, Copaifera, Peltophorum, Astronium, Tabebuia e Anadenanthera, entre outros). Entretanto, do total de espécies, pelo menos $25 \%$ pertencem ao ambiente de floresta aluvial, segundo a lista proposta por Pott e Pott (2003), incluindo espécies características, como Tapirira guianensis e Calophyllum brasiliensis, o que já é suficiente para designar a formação vegetal avaliada como Floresta Estacional Semidecidual Aluvial. No entanto, pela comparação com a mesma lista, é possível encontrar espécies como Brosimum gaudichaudii, Gomidesia sp., Ouratea sp. e Vochysia tucanorum, que pertencem à tipologia Cerrado, indicando a existência de uma faixa de transição entre esta e a formação Floresta Semidecidual.

Tabela 1. Relação de famílias e espécies amostradas na Floresta Estacional Semidecidual às margens do rio Dourados (MS).

Table 1. List of families and species sampling in the Semi-deciduous Seasonal Forest to the riverside of Dourados (MS state), Brazil.

\begin{tabular}{|c|c|c|}
\hline Famílias & Espécies & Nome comum \\
\hline \multirow{3}{*}{ Anacardiaceae } & Astronium graveolens Jacq. & guaritá \\
\hline & Myracrodruon urundeuva Allemão & aroeira \\
\hline & Tapirira guianensis Aubl. & tapiriri \\
\hline \multirow[t]{2}{*}{ Annonaceae } & Duguetia sp. & pindaíva \\
\hline & Rollinia sylvatica (A. St.- Hil.) Martius & araticum-do-mato \\
\hline \multirow[t]{4}{*}{ Apocynaceae } & Aspidosperma australe Müll. Arg. & guatambu-amarelo \\
\hline & Aspidosperma cylindrocarpon Müll. Arg. & peroba-rosa \\
\hline & Aspidosperma sp.1 & guatambu \\
\hline & Aspidosperma sp.2 & peroba-poca \\
\hline \multirow[t]{2}{*}{ Araliaceae } & Dendropanax cuneatus (DC.) Decne. \& Planch. & maria-mole \\
\hline & Didymopanax morototoni (Aubl.) Decne. \& Planch. & mandiocão \\
\hline Arecaceae & Syagrus romanzoffiana (Cham.) Glassman & jerivá \\
\hline Bignoniaceae & Tabebuia sp. & ipê \\
\hline Boraginaceae & Patagonula americana $\mathrm{L}$. & guajuvira \\
\hline \multirow[t]{3}{*}{ Caesalpiniaceae } & Copaifera langsdorffii Desf. & pau-óleo \\
\hline & Holocalyx balansae Micheli & alecrim \\
\hline & Peltophorum dubium (Spreng.) Taub. & canafístula \\
\hline Caricaceae & Jaracatia spinosa (Aubl.) A. DC. & jaracatiá \\
\hline Clusiaceae & Calophyllum brasiliense Cambess. & guanandi \\
\hline \multirow[t]{3}{*}{ Euphorbiaceae } & Sapium sp. & visgueiro \\
\hline & Sebastiania brasiliensis Spreng. & branquilho \\
\hline & Sebastiania sp. & quichabeira \\
\hline \multirow[t]{2}{*}{ Fabaceae } & Machaerium sp. & sapuvinha \\
\hline & Machaerium stipitatum (DC.) Vogel & sapuva \\
\hline \multirow[t]{4}{*}{ Flacourtiaceae } & Casearia aculeata Jacq. & guaçatunga \\
\hline & Casearia decandra Jacq. & café-de-bugre \\
\hline & Casearia gossypiosperma Briq. & espeteiro \\
\hline & Casearia sylvestris $\mathrm{Sw}$. & guaçatunga-preta \\
\hline Hippocrateaceae & Peritassa campestris (Cambess.) A. C. Sm. & - \\
\hline Lauraceae & Nectandra lanceolata Ness & canela-da-várzea \\
\hline
\end{tabular}




\begin{tabular}{|c|c|c|}
\hline Famílias & Espécies & Nome comum \\
\hline & Nectandra megapotamica (Spreng.) Mez & canelinha \\
\hline & Nectandra sp. & canela \\
\hline & Ocotea $\mathrm{sp}$. & canela \\
\hline & Ocotea velloziana (Meisn.) Mez & canelão \\
\hline Lecythidaceae & Cariniana legalis (Mart.) Kuntze & jequitibá \\
\hline \multirow[t]{3}{*}{ Meliaceae } & Cabralea canjerana (Vell.) Mart. & canjarana \\
\hline & Trichilia catigua A. Juss. & catiguá \\
\hline & Trichilia pallida $\mathrm{Sw}$. & baga-de-morcego \\
\hline \multirow[t]{5}{*}{ Mimosaceae } & Acacia polyphylla DC. & monjoleiro \\
\hline & Albizia hassleri (Chodat) Burkart & farinha seca \\
\hline & Anadenanthera macrocarpa (Benth.) Brenan & angico preto \\
\hline & Anadenanthera sp. & angico-cabelo-de-anjo \\
\hline & Inga marginata Willd. & ingá \\
\hline \multirow{3}{*}{ Moraceae } & Brosimum gaudichaudii Trécul & algodãozinho \\
\hline & Ficus guaranitica Chodat & figueira \\
\hline & Sorocea bonplandii (Baill.) W.C.Burg, Lanj. \& Wess. Boer & folha-de-serra \\
\hline Myrsinaceae & Myrsine guianensis (Aubl.) Kuntze & capororoca \\
\hline \multirow[t]{8}{*}{ Myrtaceae } & Calyptranthes concinna DC. & guamirim-de-facho \\
\hline & Campomanesia xanthocarpa $\mathrm{O}$. Berg. & guabiroba \\
\hline & Eugenia florida DC. & guamirim \\
\hline & Eugenia sp1. & pitanga \\
\hline & Eugenia sp2. & pitanga \\
\hline & Gomidesia sp. & - \\
\hline & Myrcia sp. & guamirim-da-folha-miuda \\
\hline & Myrcianthes pungens (O. Berg) D. Legrand & guabiju \\
\hline Ochnaceae & Ouratea sp. & capororoca-vermelha \\
\hline Olacaceae & Ximenia americana $\mathrm{L}$. & espinho-agulha \\
\hline Rubiaceae & $\begin{array}{l}\text { Psychotria carthagenensis Jacq. } \\
\text { Psychotria sp. }\end{array}$ & pau-de-espeto \\
\hline \multirow[t]{4}{*}{ Rutaceae } & Citrus aurantium $\mathrm{L}$. & laranja-azed \\
\hline & Citrus sp. & laranja \\
\hline & Helietta apiculata Benth. & amarelinho \\
\hline & Pilocarpus sp. & anestésico \\
\hline \multirow[t]{4}{*}{ Sapindaceae } & Diatenopteryx sorbifolia Radlk. & maria-preta \\
\hline & Dilodendron bipinnatum Radlk. & maria-pobre \\
\hline & Matayba elegans Radlk. & pau-crioulo \\
\hline & Talisia esculenta (A. St.- Hill.) Radlk. & pitomba \\
\hline & Luehea candicans Mart. & açoita-cavalo \\
\hline \multirow{2}{*}{ Ulmaceae } & Celtis pubescens (HBK) Spreng & grão-de-galo \\
\hline & Trema micrantha (L.) Blum. & candiuba \\
\hline Vochysiaceae & Vochysia tucanorum Mart. & cinzeiro \\
\hline
\end{tabular}

O Quociente de Mistura de Jentsch (QM) calculado foi de 1/7, indicando que, para cada sete indivíduos amostrados, encontrou-se uma nova espécie. Finol (1971) considera essa relação como mistura intensa em Floresta Tropical Úmida. A semelhança entre o valor obtido na floresta estudada e as florestas tropicais pode ser identificada a partir do índice obtido por HOSOKAWA (1981), que foi de 1/6, embora no caso em análise a heterogeneidade de espécies seja um pouco menor. O índice de diversidade de Simpson (Ds), com o valor de 0,95, foi superior ao encontrado por Barros (1986) em floresta tropical úmida na Amazônia brasileira, de 0,86, indicando, portanto, a alta diversidade da formação florestal analisada, confirmando o Quociente de Mistura obtido.

O índice de diversidade de Shannon (H') foi de 3,48 nats.indivíduo ${ }^{-1}$, semelhante aos valores de outras formações semideciduais, como em Bauru (SP), com 3,50 (Cavassan et al., 1984); em Matão (SP), com 3,24 (ROZZA, 1997); em Londrina (PR), com 3,90 (SILVA et al., 1998); em Conquista (MG), com 3,85 (VILELA et al., 1999) e em Itatinga (SP), com 3,77 (IVANAUSKAS et al., 1999). Valores desse índice acima de 3,11 indicam formações vegetais bem conservadas, segundo Saporetti Jr. et al. (2003), definição que se enquadra na área em estudo. 
A determinação de qual seria a diversidade clímax da formação foi calculada através do índice de eqüitabilidade de Pielou (J'), resultando em 0,80. Teoricamente, esse valor indica que seriam necessários o incremento de mais $20 \%$ de espécies para atingir a diversidade máxima da comunidade vegetal, segundo Brower e Zar (1984). Ivanauskas et al. (1999), em Itatinga (SP), trabalhando com trecho de formação florestal semelhante, encontrou valor muito próximo ao obtido nesse trabalho $\left(\mathrm{J}^{\prime}=0,82\right)$. Van Den Berg e Oliveira Filho (2000), em floresta ripária, também classificada como estacional semidecidual, encontraram $\mathrm{J}^{\prime}=0,79$.

Embora a composição de espécies não seja, sozinha, considerada um bom indicador do clímax de uma comunidade, ela é geralmente usada (ODUM, 1986). Os valores obtidos pelos índices de Shannon e Pielou, comparados com outras formações semelhantes, permitem supor que a área em estudo encontrase próxima ao clímax.

Com o índice de agregação de espécies de Morisita (Tabela 2), foi possível visualizar a distribuição espacial das espécies dentro da comunidade, característica importante para planejamento de medidas de manejo e conservação de formações florestais. Por exemplo: verificou-se que a aroeira apresenta padrão de dispersão uniforme, e se houver necessidade de reposição ou enriquecimento da área com essa espécie, o planejamento e a execução das atividades serão menos onerosas e mais simples em função da regularidade no plantio das mudas. O contrário se daria com as espécies de padrão aleatório, como é o caso do açoita-cavalo e do tapiriri.

O conhecimento prévio desses padrões permite também a sua manutenção, já que são próprios de cada espécie, que se supõe foram formados dentro de um processo de evolução que pode ter contado, por exemplo, com o tipo de dispersão de frutos e sementes, a alelopatia e as restrições edáficas, entre outros fatores. As interferências humanas podem, assim, ter maiores chances de sucesso e de permanência das características originais da formação florestal.

Tabela 2. Relação das espécies amostradas na Floresta Estacional Semidecidual às margens do rio Dourados (MS) e os respectivos índices de agregação de Morisita, os valores de $\chi^{2}$ calculados e o padrão de agregação.

Table 2. List of species sampling in the Semi-deciduous Seasonal Forest to the riverside of Dourados (MS state), Brazil, and Morisita's index, $\chi^{2}$ value and patterns of aggregation.

\begin{tabular}{|c|c|c|c|}
\hline Nome científico & Morisita & $\chi^{2}$ calc. & Padrão de agregação \\
\hline Luehea candicans & 0,80 & 41,92 & Aleatório \\
\hline Holocalyx balansae & 0,00 & & Uniforme \\
\hline Brosimum gaudichaudii & 0,00 & & Uniforme \\
\hline Helietta apiculata & 1,87 & $55,00 *$ & Tendência à agregação \\
\hline Pilocarpus sp. & 14,00 & & Agregado \\
\hline Anadenanthera sp. & 0,00 & & Uniforme \\
\hline Anadenanthera macrocarpa & 4,20 & $67,00 * *$ & Tendência à agregação \\
\hline Rollinia sylvatica & 0,00 & & Uniforme \\
\hline Myracrodruon urundeuva & 0,00 & & Uniforme \\
\hline Trichilia pallida & 0,00 & & Uniforme \\
\hline Sebastiania brasiliensis & 0,00 & & Uniforme \\
\hline Casearia decandra & 0,00 & & Uniforme \\
\hline Peltophorum dubium & 0,00 & & Uniforme \\
\hline Trema micrantha & 6,92 & $118,00 * *$ & Tendência à agregação \\
\hline Nectandra sp. & 0,00 & & Uniforme \\
\hline Ocotea $\mathrm{sp}$. & 1,50 & 47,00 & Aleatório \\
\hline Nectandra lanceolata & 0,00 & & Uniforme \\
\hline Ocotea velloziana & 0,00 & & Uniforme \\
\hline Nectandra megapotamica & 14,00 & & Agregado \\
\hline Myrsine guianensis & 0,00 & & Uniforme \\
\hline Ouratea sp. & 0,00 & & Uniforme \\
\hline Trichilia catigua & 2,59 & $114,45 * *$ & Tendência à agregação \\
\hline Vochysia tucanorum. & 0,00 & & Uniforme \\
\hline Syagrus romanzoffiana & 4,67 & $76,00 * *$ & Tendência à agregação \\
\hline Peritassa campestris & 0,00 & & Uniforme \\
\hline Casearia gossypiosperma & 2,40 & $60,60 *$ & Tendência à agregação \\
\hline Ximenia americana & 3,50 & $61,00 *$ & Tendência à agregação \\
\hline
\end{tabular}




\begin{tabular}{|c|c|c|c|}
\hline Nome científico & Morisita & $\chi^{2}$ calc. & Padrão de agregação \\
\hline Albizia hasslerii & 0,00 & & Uniforme \\
\hline Ficus guaranitica & 0,00 & & Uniforme \\
\hline Sorocea bonplandii & 2,02 & $77,72 * *$ & Tendência à agregação \\
\hline Celtis pubescens & 0,00 & & Uniforme \\
\hline Myrcianthes pungens & 0,98 & 42,67 & Aleatório \\
\hline Campomanesia xanthocarpa & 0,00 & & Uniforme \\
\hline Casearia aculeata & 0,00 & & Uniforme \\
\hline Casearia sylvestris & 42,00 & & Agregado \\
\hline Patagonula americana & 2,00 & 47,00 & Aleatório \\
\hline Eugenia florida & 0,00 & & Uniforme \\
\hline Myrcia sp. & 0,00 & & Uniforme \\
\hline Calophyllum brasiliense & 14,00 & & Agregado \\
\hline Calyptranthes concinna & 0,00 & & Uniforme \\
\hline Astronium graveolens & 0,00 & & Uniforme \\
\hline Aspidosperma sp. & 0,00 & & Uniforme \\
\hline Aspidosperma australe & 0,00 & & Uniforme \\
\hline Indeterminada 1 & 0,00 & & Uniforme \\
\hline Indeterminada 2 & 0,00 & & Uniforme \\
\hline Indeterminada 3 & 0,00 & & Uniforme \\
\hline Indeterminada 4 & 0,00 & & Uniforme \\
\hline Indeterminada 5 & 0,00 & & Uniforme \\
\hline Inga marginata & 7,00 & $59,00 *$ & Tendência à agregação \\
\hline Tabebuia sp. & 0,00 & & Uniforme \\
\hline Jaracatiá spinosa & 0,00 & & Uniforme \\
\hline Cariniana legalis & 0,00 & & Uniforme \\
\hline Citrus sp. & 0,00 & & Uniforme \\
\hline Citrus aurantium & 14,00 & & Agregado \\
\hline Didymopanax morototoni & 0,00 & & Uniforme \\
\hline Diatenopteryx sorbifolia & 1,84 & $83,00 * *$ & Tendência à agregação \\
\hline Dendropanax cuneatus & 0,00 & & Uniforme \\
\hline Dilodendron bipinnatum & 0,00 & & Uniforme \\
\hline Acacia polyphylla & 0,00 & & Uniforme \\
\hline Gomidesia sp. & 42,00 & & Agregado \\
\hline Matayba elegans & 0,00 & & Uniforme \\
\hline Psychotria carthagenensis & 2,50 & $150,75 * *$ & Tendência à agregação \\
\hline Copaifera langsdorffii & 4,50 & $65,50 *$ & Tendência à agregação \\
\hline Aspidosperma sp. & 0,00 & & Uniforme \\
\hline Aspidosperma cylindrocarpon & 3,05 & $108,54 * *$ & Tendência à agregação \\
\hline Duguetia sp. & 0,00 & & Uniforme \\
\hline Eugenia sp1. & 10,15 & & Agregado \\
\hline Eugenia sp2. & 0,00 & & Uniforme \\
\hline Talisia esculenta & 42,00 & & Agregado \\
\hline Psychotria sp. & 0,00 & & Uniforme \\
\hline Sebastiania sp. & 2,85 & $113,30 * *$ & Tendência à agregação \\
\hline Machaerium stipitatum & 0,00 & & Uniforme \\
\hline Machaerium sp. & 0,00 & & Uniforme \\
\hline Tapirira guianensis & 1,45 & 54,35 & Aleatório \\
\hline Sapium sp. & 0,00 & & Uniforme \\
\hline
\end{tabular}

$(*),(* *)$ : Diferenças significativas ao nível de $5 \%$ e $1 \%$, respectivamente, pelo teste de $\chi^{2}$.

No levantamento, $64 \%$ das espécies apresentaram padrão de dispersão uniforme, 6,5\% aleatório, $5 \%$ agregado e $24,5 \%$ com tendência ao agregamento. Padrões de dispersão aleatório e uniforme, segundo Flores (1993), caracterizam comunidades maduras. Esses valores confirmam os resultados do índice de Eqüitabilidade de Pielou, que informou que a formação florestal estudada se aproxima do clímax.

Um dado interessante desse levantamento envolve as espécies Hellieta apiculata e Cabralea canjerana, amostradas com dez indivíduos e que apresentaram o mesmo valor de índice $(1,87)$. $\mathrm{H}$. apiculata, entretanto, apresentou significância de $5 \%$ de probabilidade, com tendência ao agregamento. Para C. canjerana, o $\chi^{2}$ não foi significativo, tendo, portanto, padrão aleatório. Essa distinção torna-se 
visível quando se observa que, no campo, Hellieta apiculata concentra seus indivíduos em parcelas próximas umas das outras.

As espécies Trichilia catigua, Psychotria carthagenensis, Sorocea bonplandii, Sebastiania sp., Aspidosperma cylindrocarpon e Diatenopteryx sorbifolia apresentaram tendência ao agregamento, observada em campo.

Verifica-se, portanto, que o índice de Morisita torna-se imprescindível na conservação e no manejo florestal, pois a sua interpretação produz subsídios importantes para a elaboração de modelos de repovoamentos de áreas degradadas ou enriquecimentos de remanescentes florestais.

\section{REFERÊNCIAS}

ASSIS, M. A. de. Fitossociologia de um remanescente de mata ciliar do rio Ivinheima, MS. Dissertação (Mestrado) - Instituto de Biologia, Universidade Estadual de Campinas, Campinas, 1991.

BARROS, P. L. C. de Estudo fitossociológico de uma floresta tropical úmida no planalto de CuruáUna, Amazônia Brasileira. 1986. 147 f. Tese (Doutorado) - Universidade Federal do Paraná, Curitiba, 1986.

BRASIL. Ministério das Minas e Energia. Secretaria Geral. Projeto RADAMBRASIL: Folha SF. 21 (Campo Grande). Rio de Janeiro, 1982. 412 p. (Levantamento de Recursos Naturais, v. 28)

BROWER, J. E.; ZAR, J. H. Biotic sampling methods. In: Brower, J.E.; Zar, J.H. Field and laboratory methods for general ecology. Iowa: Wm. C. Brown, 1977. p. 65-105.

CAMPO GRANDE. Secretaria de Planejamento e Coordenação Geral. Atlas multireferencial do Mato Grosso do Sul. Campo Grande, 1990.

CARVALHO, D. A. de; OLIVEIRA FILHO, A. T. de; VILELA, E. de A. Flora arbustivo-arbórea de mata ripária do médio Rio Grande (Conquista, Estado de Minas Gerais). Cerne, Lavras, v. 2, n. 2, p. 48 68, 1996.

CAVASSAN, O.; CESAR, O.; MARTINS, F. R. Fitossociologia da vegetação arbórea da Reserva Estadual de Bauru, Bauru, SP. Revista Brasileira de Botânica, São Paulo, v. 7, n. 2, p. 91-106, 1984.

CUSTÓDIO FILHO, A.; FRANCO, G. A. D. C.; DIAS, A. C. Composição florística de um trecho de floresta pluvial atlântica, em regeneração natural após desmatamento diferenciado em Pariqüera-açu, SP, Brasil. Revista do Instituto Florestal, São Paulo, v. 6, p. 87-98, 1994a.

CUSTÓDIO FILHO, A.; FRANCO, G. A. D. C.; NEGREIROS, O. C. de; MARIANO, G.; GIANOTTI, E.; DIAS, A. C. Composição florística da vegetação arbórea da floresta mesófila semidecídua da estação ecológica de Ibicatu, Piracicaba, SP. Revista do Instituto Florestal, São Paulo, v. 6, p. 99-111, 1994 b.

DAMASCENO JUNIOR, G. A. Estudo florístico e fitossociológico de um trecho de mata ciliar do rio Paraguai, pantanal-MS, e suas relações com o regime de inundação. Dissertação (Mestrado) Instituto de Biologia, Universidade Estadual de Campinas, Campinas, 1997.

DE PAULA, J. E.; ENCINAS, J. I.; PEREIRA, B. A. da S. Inventário de um hectare de mata ripária. Pesquisa Agropecuária Brasileira, Rio de Janeiro, v. 28, n. 2, p. 143-152, 1993.

DRUMOND, M. A.; BARROS, N. F. de; SOUZA, A. L. de; SILVA, A. F. da; MEIRA NETO, J. A. A. Alterações fitossociológicas e edáficas na Mata Attântica em função das modificações da cobertura vegetal. Revista Árvore, Viçosa, MG, v. 20, n. 4, p. 451-466, 1996.

DURIGAN, G.; FRANCO, G. A. D. C.; SAITO, M.; BAITELlO, J. B. Estrutura e diversidade do componente arbóreo da floresta na Estação Ecológica dos Caetetus, Gália, SP. Revista Brasileira de Botânica, São Paulo, v. 23, n. 4, p. 371-383, 2000.

EMBRAPA. Centro Nacional de Pesquisa Agropecuária de Solos. Sistema brasileiro de classificação de solos. Rio de Janeiro, 1999. 412 p. 
FINOL, H. V. Nuevos parámetros a considerarse en el análisis estructural de las selvas virgines tropicales. Revista Forestal Venezolana, Mérida, v. 14, n. 21, p. 29-42, 1971.

FLORES, E. J. M. Potencial produtivo e alternativas de manejo sustentado de um fragmento de Mata Atlântica, município de Viçosa, Minas Gerais. Dissertação (Mestrado) - Universidade Federal de Viçosa, Viçosa, MG, 1993.

FONSECA, R. C. B.; RODRIGUES, R. R. Análise estrutural e aspectos do mosaico sucessional de uma floresta semidecídua em Botucatu, SP. Scientia Forestalis, Piracicaba, v. 57, p. 27-43, 2000.

HOSOKAWA, R. T. Manejo de florestas tropicais úmidas em regime de rendimento sustentado. Curitiba: CNPq/IBDF/UFPr, 1981. 125 p. Relatório Final.

IBGE. Manual técnico da vegetação brasileira. Rio de Janeiro. 1992.

IVANAUSKAS, N. M.; RODRIGUES, R. R.; NAVE, A. G. Fitossociologia de um trecho de Floresta Estacional Semidecidual em Itatinga, São Paulo, Brasil. Scientia Forestalis, Piracicaba, v. 56, p. 83-99, 1999.

LONGMAN, K. A.; JENÍK, J. Tropical Forest and its environment. New York: J. Wiley \& Sons, 1987.

LUDWIG, J. A.; REYNOLDS, J. F. Statistical ecology: A primer on methods and computing. New York: J. Wiley \& Sons. 1988.

NEGRELlE, R. A. B.; SILVA, F. C. da. Fitossociologia de um trecho de floresta com Araucaria angustifolia (Bert) O. Ktze. no município de Caçador-SC. Boletim de Pesquisa Florestal, Colombo, n. 24/25, 83 p. 1992.

NEGREIROS. O. C. de; CUSTÓDiO FILHO, A.; DIAS, A. C.; FRANCO, G. A. D. C.; COUTO, H. T. Z. do; VIEIRA, M. G. L.; MOURA NETO, B. V. de. Análise estrutural de um trecho de Floresta Pluvial Tropical, Parque Estadual Carlos Botelho, núcleo Sete Barras (SP-Brasil). Revista do Instituto Florestal, São Paulo, v. 7, n. 1, p. 1-33, 1995.

ODUM, E. P. Ecologia. Rio de Janeiro: Guanabara. 1986.

OLIVEIRA, Y. M. M. de; ROTTA, E. Levantamento da estrutura horizontal de uma mata de araucária do primeiro planalto paranaense. Boletim de Pesquisa florestal, Colombo, n. 4, 111 p. 1982.

OLIVEIRA, H. de O.; URCHEI, M. A.; FIETZ, C. R. Aspectos físicos e socioeconômicos da bacia hidrográfica do Rio Ivinhema. Dourados: Embrapa Agropecuária Oeste, 2000. 54 p. (Documentos, 25)

POTT, A.; POTT, V. J. Espécies de fragmentos florestais em Mato Grosso do Sul. In: COSTA, R. B. da (Org.) Fragmentação florestal e alternativas de desenvolvimento rural na Região Centro-Oeste. Campo Grande: UCDB, 2003. p. 26-52.

ROLIM, S. G.; NASCIMENTO, H. E. M. Análise da riqueza, diversidade e relação espécie-abundância de uma comunidade arbórea tropical em diferentes intensidades amostrais. Scientia Forestalis, Piracicaba, v. 52, p. 7-16, 1997.

ROZZA, A. F. Florística, fitossociologia e caracterização sucessional em uma Floresta Estacional Semidecidual. Dissertação (Mestrado) - Universidade Estadual de Campinas, Campinas, 1997.

SAPORETTI JR, A.; MEIRA NETO, J. A.; ALMADO, R. de P. Fitossociologia de cerrado sensu strito no município de Abaeté, MG. Revista Árvore, Viçosa, MG, v. 27, n. 3, p. 413-419, 2003.

SILVA, A. F. da; LEITÃO FILHO, H. de F. Composição florística e estrutura de um trecho da Mata Atlântica de encosta no município de Ubatuba (São Paulo, Brasil). Revista Brasileira de Botânica, São Paulo, v. 5, n. 1/2, p. 43-52, 1982.

SILVA, L. H. S.; KITA, K. K.; SILVA, F. das C. Fitossociologia de um trecho de floresta de galeria no Parque Estadual Mata dos Godoy, Londrina, PR, Brasil. Brasília, DF: Herbário Ezequias Paulo Hering, 1998. 62 p. (Boletim 3) 
SOARES, A. R.; SILVA, G.; DIAS, H. C. T.; GARCIA JÚNIOR, I. P. Dinâmica de populações de plantas jovens que ocorrem numa Floresta Estacional Semidecidua Montana, em Lavras, Minas Gerais. 1994. Cerne, Lavras, v. 1, n. 1, p. 28-37, 1994.

VAN DEN BERG, E; OLIVEIRA-FILHO, A. T. Composição florística e estrutura fitossociológica de uma floresta ripária em Itutinga, MG, e comparação com outras áreas. Revista Brasileira de Botânica, São Paulo, v. 23, n. 3, p. 231-253, 2000.

VILELA, E. de A., OLIVEIRA FILHO, A. T. de GAVINALES, M. L.; CARVALHO, D. A. de. Espécies de matas ciliares com potencial para estudos de revegetação no alto Rio Grande, Sul de Minas. Revista Árvore, Viçosa, MG, v. 17, n. 2, p. 117-128, 1993.

VILELA, E. de A.; OliVEIRA FILHO, A. T. de; CARVALHO, D. A. de Fitossociologia de floresta ripária do baixo Rio Grande, Conquista, MG. Revista Árvore, Viçosa, MG, v. 23, n, 4, p. 423-433, 1999.

WERNECK, M. de SOUZA; PEDRALLI, G.; KOENIG, R.; GISEKE, L. F. Florística e estrutura de três trechos de uma floresta semidecídua na Estação Ecológica do Tripuí, Ouro Preto, MG. Revista Brasileira de Botânica, São Paulo, v. 23, n. 1, p. 97-106, 2000. 